\title{
Not quite full circle? - non-racemic amino acids in the Murchison meteorite
}

\author{
from C.T. Pillinger
}

IN this issue of Nature (p.837), Michael H. Engel and Bartholomew Nagy report finding partially racemized glumatic acid, aspartic acid, proline, leucine and alanine in the Murchison meteorite. They believe the amino acids to be indigenous to the sample, even though full racemization is usually accepted as the indicator that such compounds were present before the meteorite's arrival on Earth. Nevertheless, the authors present a good case and, to their credit, make no attempt to invoke extra-terrestrial biology as an obvious and sensational interpretation of the results. Engel and Nagy only speculate that some type of stereoselective synthetic or decomposition reactions could have taken place on the meteorite's parent body. Less responsible scientists will not be so cautious or await proof that some unusual form of terrestrial contamination was not responsible for the differences between the latest results and samples previously studied.

This publication could be said (unkindly by some) to set back the study of carbonaceous substances in meteorites by some twenty years since it was in 1961 that Nagy, writing with W.G. Meinschein and D.J. Hennessy', presented the results that sparked off a decade of controversy. Using organic mass spectrometric techniques which were just finding widespread use in the petroleum industry, the group had discovered aliphatic and aromatic hydrocarbons in the Orgeuil meteorite. At the time such precise chemical structures were considered as 'chemical fossils' or 'biological markers' when found in ancient sedimentary rocks and petroleums. The analogy seemed simple - carbonaceous chondrites must be the extra-terrestrial counterparts of such materials. In voicing this conclusion, Nagy and his co-workers were following the suspicions of previous generations who, beginning with Berzelius $^{2}$, questioned whether the results of meteorite analyses were providing "a hint concerning the presence of organic structures in other planetary bodies".

After 1961, a period of vigorous activity ensued, during which many of the classes of compounds common in the Earth's sedimentary regime were located in one or other of a few known carbonaceous chondrites (see ref.3 for a review). Similarly, electron microscopic searches for microfossils were initiated and became the subject of acrimonious debate - another controversial area that has just been resurrected (H.D. Pflug, Public Lecture, Cardiff, 26 November 1981).

All the investigations faced the problem that the samples being studied were not fresh; carbonaceous chondrites are extremely porous and friable and some of the most interesting over 100 years old. Who could know what dubious fate had befallen them at the hands of loving collectors and curators? Then, in 1969, the necessary samples were provided. First, on 8 February, a large shower of material landed near Pueblito de Allende, Mexico, almost on the doorstep of the expectant Lunar Receiving Laboratory at Houston. Within possibly hours and certainly two or three days, large samples were being carefully stored free from contamination. Yet despite these precautions, appreciable quantities (1 p.p.m.) of 'biological' hydrocarbon and fatty acids were found ${ }^{4}$ in exterior, but not interior, portions of the meteorite, presumably having accrued during the brief passage through the atmosphere and sojourn on the ground. The lesson was salutary.

But Allende was still not the right meteorite: that arrived later the same year near Murchison, Victoria, Australia. Some of the first results reported for the sample concerned amino acid analyses ${ }^{5}$. By this time gas chromatographic techniques had progressed considerably and it was possible to separate amino acid enantiomers, appropriately converted to diastereomeric derivatives, on optically inactive stationary phases. Kvenvolden et al. found that the asymmetric amino acids in Murchison were fully racemized, that is, equimolar mixtures of the possible isomeric forms. Since amino acids from active biological systems are specifically laevo-rotatory or L-form, the authors were able to exclude the possibility that terrestrial organisms had contaminated their sample. Moreover, the distribution of structures was different from that encountered in biological proteins. The fact that simple molecules such as glycine, $\alpha$-amino butyric acid and $\alpha$-alanine were most prolific convinced Kvenvolden et al. that they had encountered extraterrestrial amino acids of abiūgenic origin.

The Engel and Nagy paper (see p.837) is almost entirely given over to arguments supporting their conclusion that the par- tially racemized amino acids they find in Murchison are indigenous to the sample. Briefly, these include the observation that the least racemized acids are the most difficult to extract, and the absence or only trace occurrence of common protein amino acids tyrosine, methionine and phenylalanine and the fingerprint indicators serine and threonine. Appropriate controls are offered to demonstrate that the extraction process did not cause the partial racemization or obliterate the evidence of terrestrial contamination. A selected ionmonitoring technique is used to demonstrate that the apparent inbalance in stereoisomer concentrations is not due to some unsuspected co-eluting contaminant. Finally, corroboration of the results was solicited by circulating the samples to colleagues working in the same research area. One less than satisfactory statement is the suggestion that the present study "may not contradict previous reports, because a large interior sample was analysed". Surely small samples would be expected to show inhomogeneities in distribution, not the large one.

Further examinations of amino acids from clean carbonaceous meteorites would indeed be beneficial. What is needed is an absolute indigeneity criterion, independent of stereoisomerism. Not long ago ${ }^{6}$, it was recognized that the total amino acids isolated from Murchison were isotopically very distinct from their terrestrial counterparts and polar extractables from several carbonaceous chondrites are enriched in deuterium ${ }^{7}$. Perhaps the intramolecular isotopic composition of individual enantiomers will provide the answer; not an easy measurement to perform but feasible in the long term.

Oh that Engel and Nagy had found excesses of D-amino acids, then one could accept the data or suggest some grudgebearing hoaxer had spiked the sample! But that would be even more difficult to explain. After all, we are looking for a source of abiogenically produced L-amino acids to set biochemistry on its discriminatory way.

\footnotetext{
1. Nagy, B., Meinschein, W.G. \& Hennessy, D.J. Ann. N.Y. Acad. Sci. 93, 25 (1961).

2. Berzelius Ann. phys. Chem. 33, 113 (1834)

3. Hayes, J.M. Geochim. cosmochim. Acta 31, 1395 (1967) 4. Han, J., Simoneit, B.R., Burlingame, A.L. \& Calvin, M. Nature 222, 364 (1969).

Kvenvolden, K. et al. Nature 228, 923 (1970).

6. Chang S. \& Mack. R. Lumar planet. Sci. 9, 157 (1978).

7. Becker, R.H. \& Epstein, S. Geochim. cosmochim. Acto 46, 97 (I982)
} 